\title{
飞地经济的空间生产与治理结构 基于国家空间重构视角
}

\author{
李鲁奇 ${ }^{1}$, 马学广 $2^{2}$, 鹿 宇 ${ }^{2}$ \\ (1. 华东师范大学城市与区域科学学院, 上海 200241; \\ 2. 中国海洋大学国际事务与公共管理学院,山东 青岛 266100)
}

\begin{abstract}
摘 要: 飞地经济伴随着2000年以来的区域化过程而兴起。当前研究多关注微观机制和模式, 而对宏观结构性因 素缺乏更为细致的探讨。论文基于国家空间重构理论,分析了飞地经济如何在国家空间重构中被生产出来,同时 在复杂的尺度和领域间关系中形成何种治理结构。研究表明, 在资本过度积累的危机和再领域化的驱动下, 飞地 经济产生于地方制度试验, 并因与国家空间选择性的演变趋势相一致而被纳人国家空间策略, 以培育区域竞争力 和协调区域间关系。其治理结构因涉及复杂的领域间、尺度间和政府-市场关系而存在一定内在矛盾。因此, 飞地 经济应被视为国家空间重构中的一种特殊试验手段,主要发挥“引导”作用,并同其他空间或非空间政策相衔接。
\end{abstract}

关键 词: 飞地经济; 异地共建园区; 新国家空间; 尺度重组; 区域化; 中国

2001 年以来,在由城市企业主义到区域化的多 尺度国家空间重构中, “飞地经济”这一城市合作形 式在长三角、珠三角等地区迅速发展起来并扩散到 全国,成为协调区域发展的重要空间策略。2017年 5 月,国家发展改革委员会等 8 部门联合发布《关于 支持“飞地经济”发展的指导意见》, 从国家层面对 飞地经济的总体要求、合作机制等进行了总结。 2017 年 10 月, 党的十九大报告进一步强调了区域 协调发展的重要地位, 这为发挥飞地经济在国家空 间中的作用提供了新的机遇。

“飞地经济”(Enclave Economy)存在多重含义, 通常指一国外向型或高新技术产业被国际资本所 主导而非嵌人地方经济的现象(Gallagher et al, 2007; Bustos-Gallardo, 2017), 反映了国际经济体系中边 缘国家对核心国家的依附; 同时, 它也指在移民或
少数族群内部所形成的劳动力市场, 即“族群飞地 经济” (Ethnic Enclave Economy)(Light et al, 1994; Wingfield, 2009; 李亚娟等, 2013)。2004年以来, 国 内研究逐渐赋予 “飞地经济” 新的内涵, 研究尺度逐 渐集中于区域,空间载体也以跨行政边界所共建的 产业园区为主,即“异地共建园区”(文欣中, 2004)。

在这个意义上, 国外研究多关注跨国家边界的 区域合作, 尤其是欧盟内国际合作及相应的尺度和 领域重组过程(Perkmann, 2007; Pikner, 2008; Johnson, 2009), 亦有学者关注区域内的土地利用合作 (Kwon et al, 2014)。国内研究除涉及跨国合作园区 外,对国内飞地经济的分析主要侧重以下方面: (1) 以经济资源的跨界流动为关注点, 探讨飞地经济在 区域资源配置中的功能和绩效 (孙君等, 2011; 杨玲 丽, 2015; 连莲等, 2016); (2以治理权力的跨界流动

收稿日期: 2018-05-24; 修订日期: 2019-01-08。

基金项目: 山东省自然科学基金面上项目(ZR2018MD005); 国家社会科学基金一般项目(18BJL092); 教育部人文社会科学研 究规划基金项目 (17YJA630071)。 [Foundation: Natural Science Foundation of Shandong Province, No. ZR2018MD005; National Social Science Foundation of China, No. 18BJL092; Funding Project of Education of Ministry for the Development of Liberal Arts and Social Sciences, No.17YJA630071. ]

第一作者简介: 李鲁奇(1991一), 男, 山东泰安人, 博士生, 主要从事城市地理与政治地理研究。E-mail: liluqi@outlook.com *通信作者简介: 马学广 (1979-), 男, 山东临沂人,博士, 教授, 主要从事城乡规划与区域空间治理、海洋空间规划与治理、住 房政策与土地开发管理研究。E-mail: hugeomaxg@163.com

引用格式: 李鲁奇, 马学广, 鹿宇. 2019. 飞地经济的空间生产与治理结构: 基于国家空间重构视角 [J]. 地理科学进展, 38(3): 346-356. [Li L Q, Ma X G, Lu Y. 2019. The production and governance structure of enclave economy: From the perspective of state spatial restructuring. Progress in Geography, 38(3): 346-356. ] DOI: 10.18306/dlkxjz.2019.03.005 
为关注点,探讨包括两地政府在内的多方主体间的 权力关系和制度安排(罗小龙等, 2006; 王成龙等, 2016); (3从规划和管理实践人手, 归纳总结园区合 作共建的一般机制和模式(刘永敬等, 2014; 金利霞 等, 2015; 蒋费雯等, 2016; 苏文松等, 2017)等。整 体来看, 当前研究对飞地经济的形成机制、运作模 式、经济绩效等都进行了细致分析, 对地方实践有 一定指导意义。不过, 这些文献多偏重个案化的微 观研究,尺度主要集中于区域、城市甚至园区本身, 而对其背后的宏观结构性动因和趋势缺乏更为细 致的探讨,尤其忽视对国家尺度空间重构的分析。

与此同时, 在国家空间重构研究中, 学者们也 尚未把飞地经济纳人国家空间选择性的框架。如 张京祥(2013)分析了国家战略区域规划这一尺度重 组(Rescaling)工具, $\mathrm{Wu}(2016)$ 总结了中国城市-区域 治理中国家所运用的行政区划调整、空间规划编制 和区域制度建设 3 类手段, $\mathrm{Li}$ 等(2012)总结了区域 协调发展政策、主体功能区政策、土地管理的再中心 化等中央政府所主导的区域实践等, 都尚未对飞地 经济这一新兴的国家空间重构策略给予足够关注。

在此背景下,本文将基于空间生产和国家空间重 构理论, 探讨飞地经济与国家空间重构之间的关 系。其中将重点分析飞地经济这一新的制度空间 如何在国家空间重构的背景下被生产出来, 又以何 种治理结构重构国家空间。创新点主要在于关注飞 地经济同国家空间的宏观结构性转变之间的关系。

\section{1 国家空间重构理论}

国家空间重构理论主要基于空间生产、城市和 区域治理以及国家理论而发展起来, 主要探讨 20 世 纪 50 年代以来国家空间中新的地理尺度和领域的 产生, 涉及尺度重组和领域重构(Reterritorialization) 等一系列相互交织的过程。这方面研究集中体现 在新国家空间理论中(Brenner, 2004)。该理论将国 家空间视为动态过程而非固定容器, 因此, 在全球 化、新自由主义等背景下,国家空间发生持续重构, 原有的尺度和领域结构也被重组。此外, 相比于以 往研究, 这一理论强调国家权力在全球化中并非受 到侵蚀, 而是通过空间选择性(Spatial Selectivity)赋 予特定尺度和领域一定的优先性, 以引导国家空间 中的资本循环。例如国家可通过区域规划推进区 域一体化、培育区域国际竞争力, 从而在全球化中
获得竞争优势。

国家空间选择性体现为面向国家机构内部的 “国家空间项目”(State Spatial Projects)和面向外部 社会经济活动的“国家空间策略” (State Spatial Strategies), 前者如治理权力的上收或下放、行政区 划调整,后者如区域和城市规划、新城建设等。在 变化趋势上, 国家空间选择性在中心化和去中心 化、统一性和定制化等维度间变动, 例如 20 世纪 70 年代以来,西欧和北美等地在城市和区域治理上出 现了明显的去中心化趋势,城市政府获得了更大的 自主权，同时空间政策日益朝向定制化、差异化方 向发展, 以满足不同城市和区域的发展需求。在作 用方式上，国家空间政策通常通过分层(Layering)的 方式重构国家空间，而非进行剧烈的、全新的重 构。这个过程包含了试错性的政策试验, 以探索新 的重构策略并将其叠加于国家空间及原有重构策 略上, 进而推动国家空间路径依赖式的演进,形成 “马赛克”式国家空间形态。例如近年来中国密集 推行的国家级新区、城市群、主体功能区、自由贸易 试验区等一系列规划,这些规划在空间上、功能上 可能存在重叠, 在实施效果上也参差不齐, 但通过 这种政策的试验和分层叠加, 能够推动国家空间 (不均衡地)动态重构, 以实现提高区域国际竞争力、 协调区域间发展等目标。

\section{2 从城市企业主义到区域化的国家空 间重构}

\section{1 中国城市企业主义的兴起与危机}

1970 年后, 伴随西方福特-凯恩斯主义的解体 和新自由主义的发展, “城市企业主义”(Urban Entrepreneurialism) 在西方逐渐兴起 (Harvey, 1989)。 其特征在于以创新性战略保持或提高城市竞争力, 以企业主义方式提出和执行这些战略, 以企业主义 的话语营销城市(Jessop et al, 2016)。

新中国成立后, 中国实行高度集中的计划经 济, 国家尺度在公共管理和社会经济发展中占据主 导地位。该阶段国家空间组织以劳动地域分工为 主要原则, 实行相对均衡的空间政策。改革开放 后, 伴随外资的涌人和市场经济的发展, 城市直接 暴露于国际和区域竞争中,行政权力也逐渐由中央 下放到地方。尤其在 1994 年的分税制改革中, 中央 政府财政收人占全国的比重上升为 $55.7 \%$, 对地方 
的财政转移所发挥的作用也日渐减弱(李昕等, 2012), 但地方政府在经济管理上仍保留了较大的 自主权, 官员的绩效评估也日益以经济发展为导 向。在此背景下, 为扩大税收并提高经济竞争力, 城市政府开始大量进行土地征收和开发。由于土 地管理权限在 1986 年的《土地管理法》中被下放到 地方, 加之土地转用过程中存在的巨大收益, 土地 的征收和出让成为地方政府财政收人的重要来源, 由此形成“土地财政”现象。同时, 为吸引国际和国 内资本, 城市政府常常进行地方营销、税收优惠、资 金补贴等,并与企业建立互惠的增长联盟。此外, 资本的再领域化也剧烈地重塑了建成环境, 表现为 基础设施建设的热潮等。

中国城市企业主义的兴起体现了尺度上去中 心化和领域上定制化的国家空间项目转型, 推动了 城市尺度的兴起以及沿海地区和中心城市的迅速 发展, 使中国得以进一步融人世界资本主义生产体 系。不过, 这一治理策略的调整也产生了一系列危 机。从城市间关系上看, 竞争加剧和缺乏合作导致 城市间产业同构现象明显、基础设施重复建设且衔 接不畅,形成行政区经济; 核心与边缘地区之间的 发展差距也进一步加大, 剥夺了落后地区的发展权 利。从城市内部来看, 大量的土地征收和基础设施 建设导致土地利用破碎化、城市用地蔓延; 高污染 企业的进人也导致城市环境问题恶化; 同时土地财 政具有不可持续性, 而高优惠的引资策略也导致大 量财政收人流失并加剧城市财政风险。

\section{2 城市企业主义危机驱动下的区域化}

2001 年后, 中国国家空间开始选择性朝向中心 化、平等化等方向发展(表 1), 以缓解恶性竞争、缩小 发展差距、应对城市土地利用问题等。具体来看, 主 要有以下 4 类手段( $\mathrm{Li}$ et al, 2012; Wu, 2016)。首先 是权力上收, 主要表现为 1998 年后土地管理的收 权。由于土地管理权的下放引发了耕地破坏、城市
蔓延、低价出让等问题，因而通过《土地管理法》的 修订和行政机构调整, 土地利用形成自上而下层层 分解的配额式管控体系,城市政府则通过指标争取 和交易等进行开发。其次是撤县设区、省直管县等 行政区划调整,主要为应对市带县体制下市县间的 恶性竞争、基础设施衔接不畅以及市对县的“剥削”等 问题, 以提高城市税收和资源调动能力。再次是区 域规划的兴起, 由于国家在区域规划审批甚至编制 中发挥关键作用,因此这成为国家协调空间发展最 直接的手段,具体涉及主体功能区规划、城镇体系规 划和城市群规划等。最后是跨界区域合作的兴起 (马学广, 2016), 具体形式如合作论坛、合作协议、正 式或非正式的区域协调组织等, 这种合作通常是自 下而上的,但省政府和中央政府也常发挥协调作用。

不过,这一区域尺度重组仍贯穿了城市企业主 义的逻辑,其动因仍是为破除经济发展障碍、提高 城市自身竞争力,本质上是城市企业主义在区域尺 度的延伸。同时,为解决新的区域间发展不均衡问 题, 区域协调发展战略也在 2000 年后全面实施。

\section{3 飞地经济的发展、分布与类型}

在由城市尺度到区域尺度的国家空间重构中, 飞地经济作为一种新兴的空间重构策略开始被城 市、区域和国家等不同尺度的行动者所重视。该部 分将简要分析飞地经济的发展过程, 并对其分布和 类型进行简要总结。

\section{1 地方制度试验中的飞地经济}

飞地经济是地方制度试验的产物, 最早产生于 长三角、珠三角和京津冀等经济水平较高、经济体 制改革较为深人的地区,并多集中于各区域内部。 长三角地区的江阴-靖江工业园区早在 2002 年就已 提出, 是国内最早的飞地经济实践之一。2005 年江 苏省在出台《关于加快南北产业转移意见的通知》

表 1 中国国家空间选择性的演变轨迹

Tab.1 Trajectory of state spatial selectivity in China

\begin{tabular}{llll}
\hline \multicolumn{1}{c}{ 历史阶段 } & \multicolumn{1}{c}{ 国家空间选择性形式 } & \multicolumn{1}{c}{ 城市区域治理形式 } & 主要冲突和矛盾 \\
\hline 改革开放前 & 以国家尺度作为空间治理的首要 & 计划经济下层级化的规划协调 & 城乡二元结构 \\
$(1949-1978$ 年 $)$ & 尺度 & & \\
改革开放初期 & 地方的崛起;大城市占据主导地位 & 城市企业主义;规划权限的下移 & 城市间竞争加剧;行政区经济; 不 \\
$(1979-2001$ 年 $)$ & & & 可持续的发展 \\
加人WTO后 & 朝向城市-区域的尺度上移 & 权力上收; 选择区划调整;空间规 & 区域认同的缺乏; 国家主导的尺 \\
(2001年至今 $)$ & & 划;跨界合作 & 度重组 \\
\hline
\end{tabular}


后开始了大规模的苏南、苏北园区共建, 成为长三 角甚至全国飞地经济的典范。同时, 上海张江平湖 科技园区、上海漕河泾开发区盐城分区等跨省实践 也随之兴起。珠三角地区的飞地经济主要依托 2008 年后广东省的 “双转移” 政策而大规模发展起 来,截至 2016 年已达 83 家, 如深汕特别合作区、广 州(梅州)产业转移工业园等。京津冀地区的实践亦 强调产业转移和合作, 并同京津冀协同发展战略相 联系, 如 2015 年的《京津冀协同发展规划纲要》对产 业转移问题进行了研究, 随后跨省的飞地经济在河 北逐渐发展起来,如曹妃甸协同发展示范区、威县. 顺义产业园等。在全国其他地区, 飞地经济也大量 兴起,如湖北武汉与黄冈2 014 年开始的园区共建、 四川成都与德阳在 2013 年建立的成德工业园等。 这其中, 也包括一定的跨区域实践, 如深圳与河北 保定 2016 年签署共建的“保定深圳园”。此外,与飞 地经济相关的区域性非营利组织也逐渐产生, 如长 三角园区共建联盟、广东省工业园区协会等。

\section{2 国家空间政策中的飞地经济}

地方制度试验中的飞地经济多集中于区域内 部, 而在国家尺度, 除培育区域竞争力外, 协调区域 发展差距同样是重要关注点, 因此中央政府更强调 飞地经济与各类对口支援和帮扶等政策的衔接, 以 缩小中西部地区与东部地区间的发展差距。尽管 在地方制度试验中, 飞地经济早在 2003 年就已产 生, 但在 2008 年汶川地震的灾后重建规划中才受到 国务院关注。此后, 除针对重庆、内蒙古、江西等省 区的专项文件外, 飞地经济也直接同西部大开发、 中部崛起等区域发展政策相结合, 如 2010 年的《国 务院关于中西部地区承接产业转移的指导意见》即 强调园区共建在带动中西部发展中的作用。与此 同时, 区域内的飞地经济亦受到国家关注, 并同长江 经济带发展、泛珠三角区域合作等战略相结合, 以 推进区域一体化、提高区域竞争力。在此基础上,飞 地经济进一步被纳人全国性的空间政策,并同国土 开发、生态补偿、农民工返乡创业等一系列空间或 非空间政策相衔接。如 2017 被正式纳人全国国土 规划纲要,标志着飞地经济由自下而上的制度试验 正式转变为国家尺度的空间发展战略。在国家发 展改革委员会等部门联合发布的《关于支持“飞地 经济”发展的指导意见》中, 亦肯定了飞地经济在区域 化中的作用, 并进一步将其与三大国家战略相联 系。在这些政策的指导下, 全国尤其是中西部地区
的飞地经济依托对口援建或帮扶等项目发展起来, 如喀什深圳产业园、凯里 ·杭州经济开发区协作园 等。

\section{3 飞地经济的分布与类型}

基于网络资料, 针对各省区分别进行检索,截至 2017 年底共整理得到全国 351 个共建园区(图 1)。 从核密度上看, 飞出地高度集中于京津冀、长三角 和珠三角三大城市群, 在中部地区也有零星分布; 而飞人地则相对分散,在中部形成纵向轴带, 在东 北、成渝等地区也呈团块状分布,但仍主要集中于 江苏和广东。根据飞出地与飞人地的空间距离将 其分为 4 级, 可发现强烈的距离衰减特征。其中 $506.4 \mathrm{~km}$ 以下的飞地经济有 224 个, 占总数的 $63.8 \%$, 主要分布于沿海地区和成渝地区, 多以区域 中心城市为核心向周边扩散;506.5 1214.0 km共有 71 个, 仍主要以三大城市群为核心呈扇形向中部地 区和东部其他地区扩散; 其余 2 级则分别包含 39 个 和 17 个长距离联系, 主要存在于东部地区与中西部 地区之间,以及东部部分城市群之间。

在飞地经济的分类上,当前研究多基于投资和 产业发展模式进行总结(蒋费雯等, 2016; 苏文松 等, 2017), 但这些分类较为微观, 难以把握飞地经 济与国家空间重构之间的关系。因此, 本文从领域 范围和开发管理模式 2 个维度出发, 总结出 8 种飞 地经济类型(表2)。

从领域范围上看, 飞地经济可表现为区域内合 作和跨区域合作。前者通常以地方政府为主导, 以 产业转移、提高区域竞争力为基本目标, 多存在于 东南沿海地区; 后者亦可以地方政府为主导,但常 常贯穿了中央的政策导向(如西部大开发政策、全 国国土规划), 以产业转移、对口援建等为目标, 多 存在于东部地区与中西部地区之间。二者的根本 区别并非在于空间范围的大小, 而在于目标或功能 的不同: 前者目标在于推进区域化、增强城市-区域 的竞争力, 同朝向关键区域的国家空间重构趋势相 一致; 后者则是为协调区域间关系、缩小区域发展 差距,更多依托中央的政策导向。

在开发管理模式上, 飞地经济主要存在以下几 种类型: (1) 飞出地主导模式, 主要由飞出地进行投 资, 开发建设和日常运作也多依托飞出地的开发 区、政府或投资公司; (2) 飞人地主导模式,管理和开 发机构主要由飞人地领导, 规划、建设和招商等工 作也主要依托所在地, 而飞出地则主要负责协助招 
(a) 飞出地分布

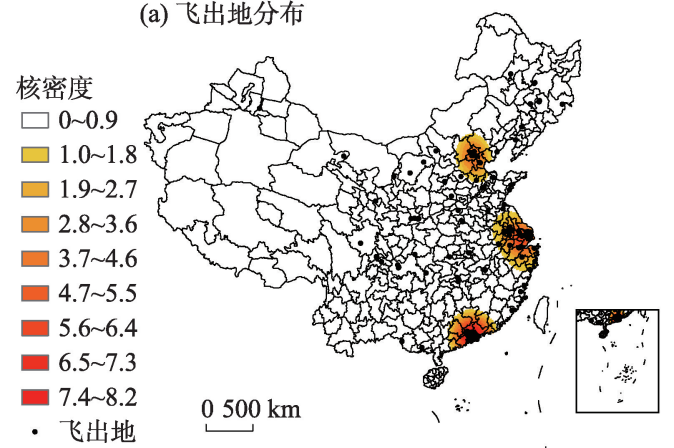

(c) 短距离联系

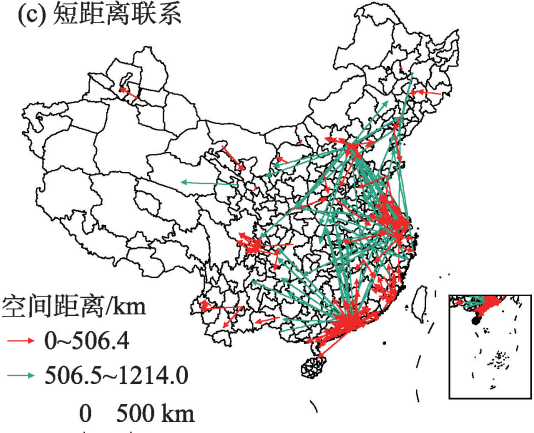

(b) 飞人地分布

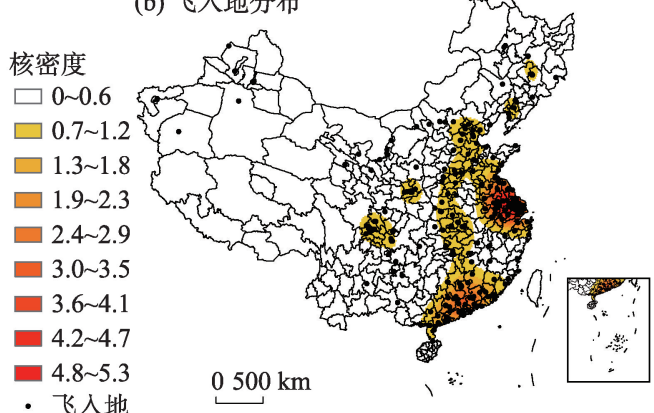

(d) 长距离联系

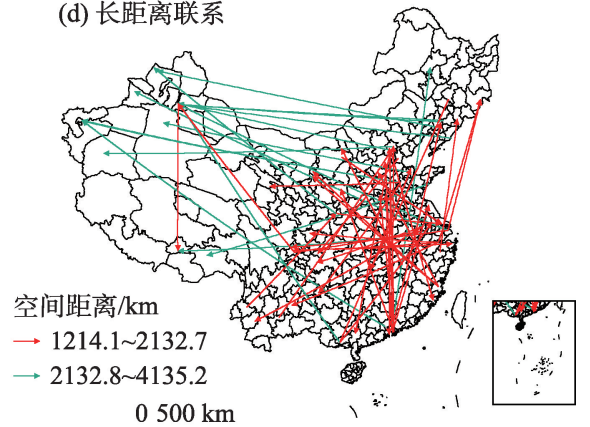

注: 本图根据网络资料整理绘制,基于国家测绘地理信息局标准地图服务网站下载的审图号为 GS(2016)2887 号的标准地图 制作, 底图无修改。

图 1 飞地经济的空间分布与空间联系

Fig.1 Spatial distribution and connections of enclave economy

表 2 飞地经济的主要类型及典型案例

Tab.2 Major types and cases of enclave economy

\begin{tabular}{cll}
\hline 开发管理模式 & \multicolumn{1}{c}{ 区域内合作 } & 跨区域合作 \\
\hline 飞出地主导模式 & 苏州宿迁工业园区 & 罗星永新工业园 \\
飞人地主导模式 & 深圳福田(和平)产业转移工业园 & 南疆齐鲁工业园 \\
双方共管模式 & 东莞石碣(兴宁)产业转移工业园 & 郎溪(中国)经都产业园 \\
多尺度参与模式 & 深汕特别合作区 & 湖北深圳工业园 \\
\hline
\end{tabular}

商等工作; (3) 双方共管模式, 多由两地共同出资, 并 共同负责园区的规划、开发、管理等事务; (4) 多尺度 参与模式, 不仅涉及飞出地和飞人地, 同时其他尺 度主体(尤其是省区政府)也在协调、投资、开发等事 务中发挥关键作用, 园区管委会甚至在名义上受省 政府领导。

\section{4 飞地经济的空间生产机理}

飞地经济作为一种新的制度空间, 在根本上由 资本的空间运动所驱动, 同时也是地方和国家制度 试验的一部分, 在复杂的国家空间重构过程中被塑 造, 以进一步重构国家空间(图2)。该部分将基于这
一思路对飞地经济的空间生产机理进行简要论述。

\section{1 不均衡空间发展与资本的再领域化}

尽管资本主义在根本上试图朝向均衡化发展, 以生产出均质化和一体化的空间, 但从具体劳动的 角度看, 不均衡发展同样是资本主义的内在属性 (Smith, 1990)。在这个过程中, 资本日益集中地附 着于特定地理空间,并由于特殊的区位优势获得超 额利润; 但这种“附着”表现为难以流通的固定资本 和本地劳动力市场, 其地方根植性使资本的空间转 移面临一定障碍(Harvey, 1982)。在此背景下, 资本 过度积累的危机日益集中于特定空间及其建成环 境中, 而解决危机的方法则是将资本从这一空间中 解放出来, 寻找新的可以获得超额利润的空间, 以 


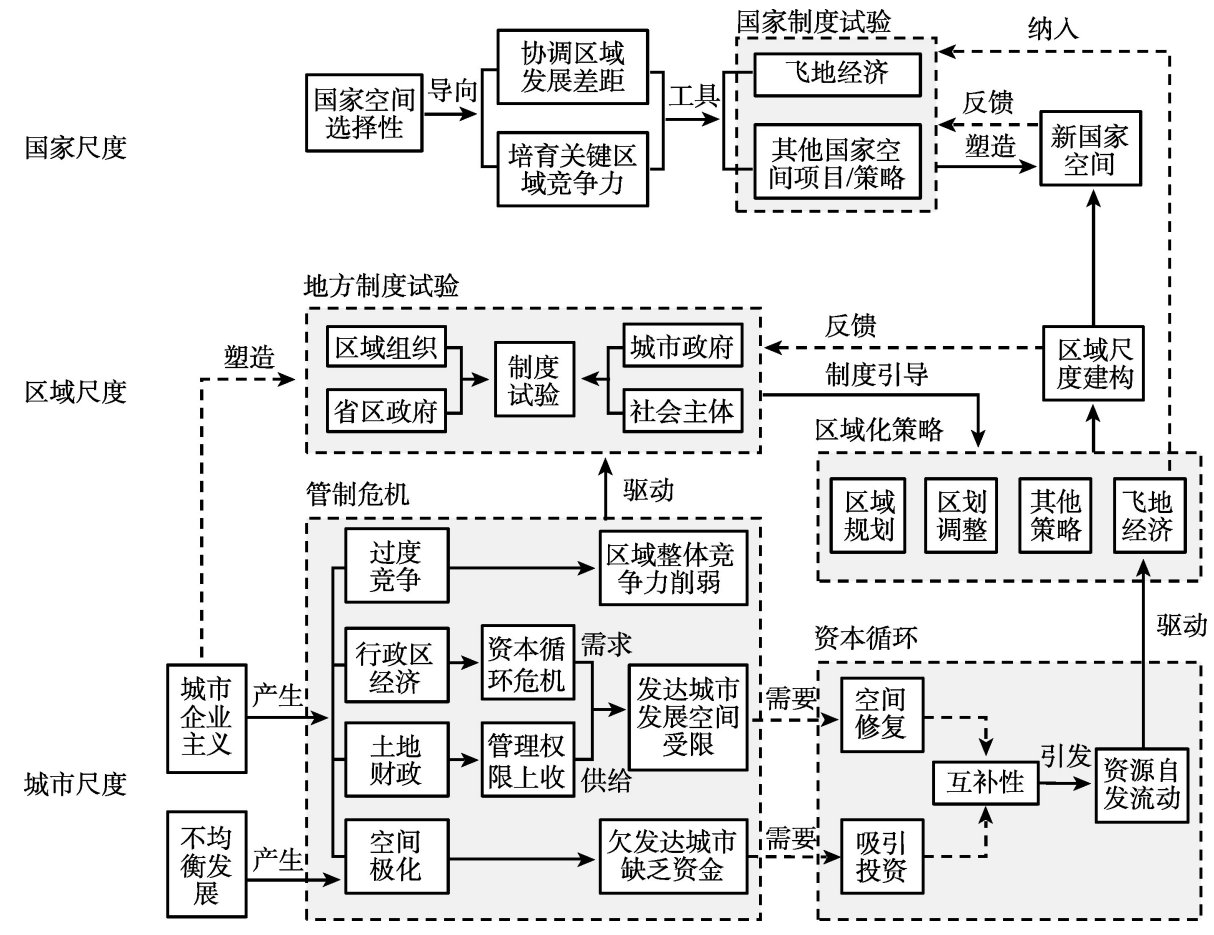

图 2 飞地经济的空间生产机理

Fig.2 Mechanism of enclave economy's production

实现空间修复。这种不均衡地理发展下的去领域 化和再领域化过程表现为 “蛙跳式” 的资本空间运 动(Smith, 1990), 成为中国社会主义市场经济体制 下飞地经济形成的根本驱动力。

改革开放以来,在经济较为发达的部分中心城 市,资本因过度积累而趋于饱和(表现为基础设施的 重复建设等), 土地、劳动力等要素也日益紧张, 集 聚不经济现象日益突出,严重制约城市发展。同时, 分权化下地方主义的盛行导致城市间竞争加剧, 使 得城市即使出现过度积累的危机也不愿进行产业 转移, 以免产生税收流失、就业率下降等问题。更 严重的是, 土地财政导致了不合理的土地利用模 式,引发土地管理权的上收和耕地保护政策的收 紧,加剧了土地资源的紧张局面。在此背景下, 企 业经营成本急剧上升, 因区位优势、集聚经济等获 得的超额利润逐渐降低, 故开始进行自发迁移, 如 深圳在 21 世纪初所发生的大规模企业外迁现象。 这对企业和城市政府均造成一定损失, 如企业增加 固定资产投资,政府则税基减小。而以飞地经济为 形式,基于城市间经济互补性进行有组织的蛙跳式 企业外迁, 则能降低企业经营成本, 同时通过“权力 的再领域化”保证飞出地政府继续获得一定的税 收、分红等收益。因此, 飞地经济本质上是由政府 协调的、有组织的资本再领域化和空间修复形式。

\section{2 行政区经济下的试验区域主义}

行政区经济加剧了城市本身资本过度积累的 危机,也导致区域内发展差距加大, 严重制约区域 竞争力的提高。在此背景下,与同城化、市长联席 会议等区域化试验类似, 飞地经济也成为破解行政 区经济的一种制度试验。

改革开放以来,在“摸着石头过河”原则指导 下,中国的经济体制改革(如经济特区的设立)形成 强烈的试验属性, 其基本逻辑是试验一总结一推 广。相应地, “试验区域主义”(Gualini, 2004)也成为 当前区域尺度重组的重要方式。而飞地经济正产 生于地方治理试验,如江阴-靖江工业园区被称为 “文件上没有、惯例上没有、领导讲话里暂时还没有 的创新和突破”。相比于其他制度试验, 飞地经济 具有更大的灵活性。如在空间范围上可同时用于 协调区域内和区域间关系; 在制度安排上不需要进 行剧烈的行政组织重构,政治和经济风险相对较 低; 在参与主体上飞出地与飞人地的双边关系更容 易协调,合作成功率也更高。

作为制度试验, 飞地经济的产生需要较为宽松 的制度环境、良好的地缘和人缘条件,甚至富有改 革精神的官员等。飞地经济最早产生于珠三角、长 三角等改革较为深人、思想较为开放的地区,而在 中西部等地区则易受观念和行政体制的制约。同 
时, 飞地经济以短距离联系为主,集中于区域内部, 甚至直接依托城市间对口帮扶而发展起来。这是由 于飞地经济本质上是城市间重复博弯的结果, 而地 缘相近或有长期合作关系的城市在长期互动中更 容易关注长期利益并进行合作。此外, “试验”的本 质是基于某种假设而进行尝试, 通常面临较大的失 败风险, 因此具有冒险和改革精神的试验者常常发 挥关键作用。例如在江阴-靖江工业园区和深汕特 别合作区的建设中, 均有省政府和各市特定官员的 支持和推动。总之, “试验” 属性决定了飞地经济的 产生是一系列必然和偶然因素交互作用的结果, 而 一旦成功, 其经验就具有积累性和可推广性, 这成 为广东、江苏等地飞地经济迅速发展的重要原因。

\section{3 面向区域尺度的国家空间选择性}

国家空间选择性体现了国家对特定尺度和领域 的偏好, 这种偏好使其通过国家空间项目或策略引 导国家机构和社会经济空间的重构(Brenner, 2004)。 2001 年以来, 中国的国家空间选择性在尺度上日益 关注区域,在领域上则重点关注有全球竞争力的关 键城市一区域, 并兼顾区域间的协调发展。在此背 景下，飞地经济从自下而上的制度试验上升为国家 空间策略, 并叠加于城市群规划、西部大开发等原 有策略上,成为国家空间重构的新兴手段。

在中国的区域尺度重组中, 国家空间政策主要 关注以下 2 个方面。首先, 与西欧新一轮国家空间 重构类似(Brenner, 2004), 在区域尺度上应对城市 企业主义的治理危机、提高区域竞争力是首要关注 点, 如 2016 年的《长江三角洲城市群发展规划》明确 提出 “长三角城市群是我国参与国际竞争的重要平 台”。而飞地经济既为中心城市产业转型升级提供 了空间, 又能使边缘城市获得发展要素, 故在推动 区域一体化、提高区域整体竞争力中发挥重要作 用。其次, 以区域为单元培育国际竞争力可能加剧 区域间的不均衡格局。为此,中国区域政策在 2000 年以来也开始重视区域协调发展, 出台了西部大开 发等一系列政策。在这个过程中, 飞地经济的优势 再次显现出来。相比于一般的跨界合作, 飞地经济 将资源集中于园区, 有利于发挥集聚效应并培育增 长极; 而相比于一般的产业园区, 飞地经济是一种 结对式、稳定持续的合作, 有利于城市间长期合作 制度的建立和发展模式的探索。这一优势加之空 间范围上的灵活性使其成为协调区域发展的有力 工具, 使国家在培育关键区域竞争力的同时, 缓解
区域尺度上新的空间极化问题,促进全国尺度资源 的优化配置。

\section{5 飞地经济的治理结构及其内在矛盾}

飞地经济存在灵活多样的治理结构, 综合当 前飞地经济实践, 可将其一般治理结构总结如下 (图 3)。在主体上, 飞地经济可涉及两地政府或开发 区、中央或省级政府、政府间协调组织、管理和开发 主体等。其中, 飞出地和飞人地城市政府以及管委 会通常是飞地经济最基本的治理主体。除城市政 府外, 飞地经济也常常依托飞出地或飞人地开发区 设立,管委会也受开发区领导。同时为协调城市间 关系, 两地主要领导可成立联席会议或领导小组, 决定开发建设中的重大事项。在管理和开发上,飞 地经济通常采取市场化运营, 出资成立开发公司或 委托第三方。此外在省内和跨省实践中,省级政府 也常直接参与到飞地经济建设中, 或间接地提供政 策支持; 中央政府较少直接参与, 而通常在区域政 策和飞地经济专项政策等方面提供指导和支持。

可以发现,飞地经济中主要涉及3 对关系: 领域 间关系、尺度间关系、政府一市场关系。这决定了飞 地经济相比于国家级新区等新的制度空间,治理结 构更为复杂。尽管复杂的治理结构可用来协调多种 主体间复杂的利益关系,但由于各主体均追求自身 利益最大化, 飞地经济中的结构性矛盾也常常凸显。

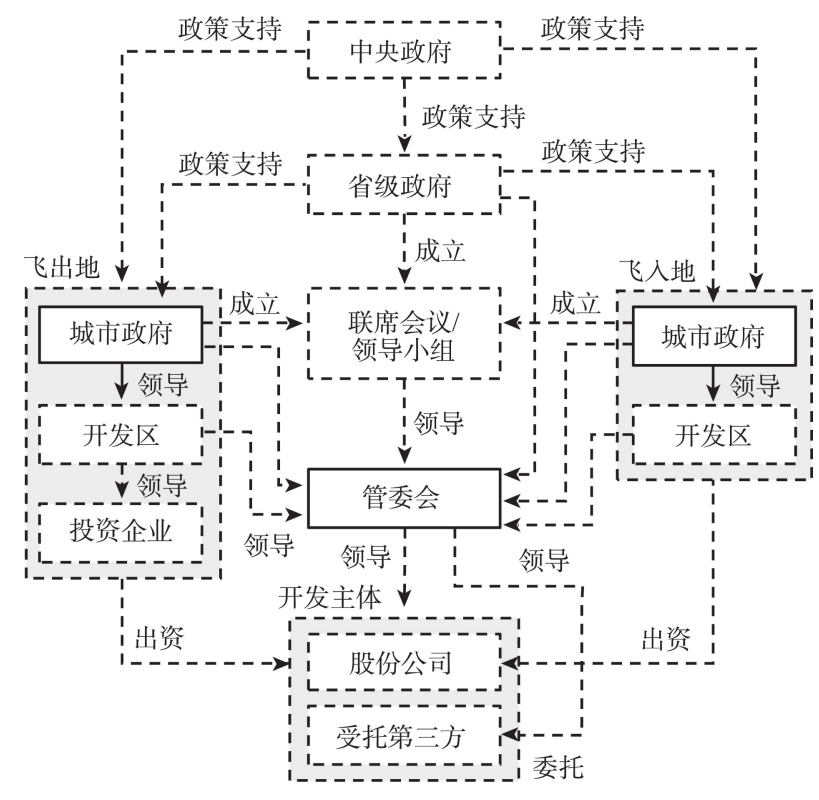

图 3 飞地经济的一般治理结构

Fig.3 General governance structure of enclave economy 
在城市间关系上, 飞地经济不仅涉及资本的再 领域化, 也涉及权力的再领域化, 是典型的领域政 治问题。领域(Territory)的本质在于特定权力主体 对一定有界空间的占有(Delaney, 2005), 这种占有 具有排他性并直接服务于权力主体自身利益。相 比于同城化、跨界园区等再领域化过程, 飞地经济 的特点在于飞出地在原有行政安排下完全缺乏对 园区土地的管辖权, 它在园区的权力完全来自飞人 地的让渡(有时也来自上级政府的授予)。这一领域 权力格局的潜在问题在于, 飞人地对园区仍保持名 义上或事实上的管辖权(如社会管理权力), 且对飞 出地权力的 “侵人”相当敏感, 因此当利益格局发生 变化时, 飞人地可能试图收回或干扰飞人地在园区 的权力, 如靖江对封闭运作的江阴-靖江工业园区 的介人(张京祥等, 2011)。此外, 当飞地经济带动起 由飞出地到飞人地的产业转移浪潮时, 飞人地也可 能积极扶持无需权力和利益分享的开发区, 并同共 建园区进行竞争。

这一问题除源自权力再领域化本身的性质、城 市间在观念和利益方面的分歧外，也同飞地经济中 贯穿的城市企业主义逻辑紧密相关。尽管飞地经济 是一种区域化制度试验, 但仍受城市企业主义治理 模式的影响。对于飞出地和飞人地来说, 飞地经济 均体现了强烈的发展和竞争导向(如腾笼换鸟或实 现经济起飞), 城市自身利益和竞争力始终是参与方 的首要关注点。同时, 飞地经济是一种新兴的土地 开发模式, 土地财政在一些城市仍是开展飞地经济 的动因之一, 如 2010 年湖北襄柇深圳工业园的违规 土地开发。在这一逻辑下, 城市间以及政府、企业、 居民等主体间极易陷人利益争夺而阻碍合作进程。

从尺度上看, 飞地经济常涉及省区或中央政府 等高尺度行动者, 这一复杂的尺度间关系亦产生一 系列矛盾。高尺度行动者在飞地经济中主要扮演 两种角色。其一是不直接参与飞地经济的开发管 理, 但在土地、税收、人事等方面对城市政府具有领 导权。因此当上级政府态度不积极时, 飞地经济可 能在土地审批等方面受到牵制, 城市官员也可能考 虑到潜在政治风险而裹足不前。其二是高尺度行 动者直接参与飞地经济建设, 发挥协调作用并提供 政策和资金支持。尽管这有利于飞地经济的有效 实施, 但参与主体的增加也使权力和利益结构进一 步复杂化, 在人事安排、税收分成等方面产生矛 盾。同时, 由于飞地经济对区域政策(如广东省双
转移政策、江苏省沿江开发政策等)具有强烈的依 赖性, 当高尺度政策发生变动时, 飞地经济也将呈 现出明显的脆弱性和不稳定性。

此外,共建园区具有开发区的一般属性, 如吸 引投资并促进产业发展,进而带动地区经济增长。 因此, 它也有开发区这一特殊制度空间的各类结构 性矛盾,如管委会与地方政府之间的矛盾、产业发 展问题等。其中, 产业转移是飞地经济的基本功能 (因对口帮扶而共建的园区也常常具备产业转移功 能), 但这一过程中可能导致飞人地环境恶化、飞出 地产业空心化等问题。同时, 飞人产业和本地产业 链不衔接、规划选址不科学、飞人地要素价格上涨、 飞人地行政管理效率低下等问题均可对园区产业 发展形成制约,进而威胁合作的稳定性。

从实际效果上看, 飞地经济在区域发展中的作 用也参差不齐。例如, 制度建设较为完善、资源投 人较为充分的深汕特别合作区已成为深圳的一座 “新城”, 在缓解深圳土地紧张问题、带动粤东经济 发展等方面发挥了有效作用。然而,仍有部分飞地 经济在发展过程中面临日益严峻的管理体制和经 济发展困境, 如江阴-靖江工业园区联动开发协调 会曾一度中断,两地在实际管理中也存在大量冲 突。此外,亦有大量飞地经济因后续投资和管理不 到位、产业规划不合理、土地利用违规等问题而举 步维艰。

综合以上分析, 飞地经济反映了中国的新国家 空间与西欧“尺度重组的竞争国家体制”(Rescaled Competition State Regime, RCSR)之间的相似性，二 者均关注区域等次国家尺度, 具有强烈的竞争导向, 同时是不稳定的、动态的马赛克式空间(Brenner, 2004)。飞地经济正是这一国家空间中一种新兴的 重构策略,它试图突破行政区经济和城市企业主 义, 建构区域尺度并协调区域间发展, 但又因复杂 的领域和尺度间关系而内含一系列结构性矛盾和 冲突,并与国家级新区、区域规划等其他“分层”的 国家空间策略一同塑造了马赛克式的新国家空 间。从这个意义上看, 飞地经济是中国当前国家空 间重构中的一种特殊现象, 它并未正面解决行政区 经济问题(文欣中, 2004), 只是在原有制度框架下试 图重构领域间关系的一种灵活的试验手段。因此, 飞地经济应同其他空间或非空间政策相配套, 在国 家空间重构中更多地发挥“引导”作用, 为更深人的 城市间合作汼线搭桥、提供初步平台。 


\section{6 结论与讨论}

本文基于国家空间重构理论,分析了飞地经济 这一新兴国家空间策略的空间生产和治理结构。 主要研究结论如下:

（1）飞地经济产生于中国国家空间重构的宏观 背景下, 是国家空间选择性由城市尺度向区域尺度 转移的过程中所产生的新兴治理策略。因此, 在个 案化的微观研究之外, 亦应将飞地经济置于这一宏 观结构性变化中进行分析, 以进一步把握其机理和 意义。

(2) 飞地经济在长三角、珠三角、京津冀等经济 水平较高、改革较为深人的地区发展较为成熟, 2008 年后也逐渐被国家所关注,并同其他国家政策 相衔接。在空间分布上具有强烈的距离衰减特征, 多集中于短距离、区域内。同时基于领域范围和开 发管理模式两维度可总结为 8 种类型。其中在领域 范围上, 飞地经济既可用于推进区域一体化, 又可 用于协调区域间关系,这一灵活性使其同时被地方 和中央所重视。

(3) 在空间生产机理上, 资本过度积累的危机 以及相应的再领域化(或空间修复)是飞地经济兴起 的根本驱动力。在这一资本的驱动下和行政区经 济的限制下，飞地经济在地方制度试验中产生，以 破解城市企业主义的危机; 这种试验是一系列必然 和偶然因素交互作用的结果,但具有积累性和可推 广性。由于同国家空间选择性的演变趋势相一致, 飞地经济也被纳人国家空间策略,作为培育关键区 域竞争力、协调区域间发展的新兴手段, 从而进一 步推动国家空间的重构。

（4）相比于其他空间重构策略, 飞地经济在治 理结构上较为复杂, 涉及领域间关系、尺度间关系、 政府一市场关系。这一结构存在一系列内在矛盾， 如飞出地再领域化的权力与飞人地原有领域权力 间的矛盾、尺度间在行政管理和政策支持等方面的 问题等。这使得飞地经济呈现出一定的脆弱性和 不稳定性, 表明其仍是国家空间动态重构中的特殊 试验手段,其作用的发挥需同区域规划、政府体制 改革等其他空间或非空间政策相配套。

尽管飞地经济存在一系列结构性矛盾, 实际效 果也参差不齐, 但相比于行政区划调整等重构策 略, 具有更强的灵活性。因此, 应将飞地经济的作 用定位为“引导”,即为区域内或跨区域的城市间合
作牵线搭桥,为资本等要素的流动提供初步的制度 通道和空间依托, 在此基础上进一步推动更大范 围、更深层次的合作。在这个过程中,欠发达的飞 人地尤其应重视长远利益, 关注飞地经济所带来的 管理经验、思想观念、人才和技术等先进要素,并积 极进行行政体制改革、提高行政效率,避免因对短 期经济利益的争夺而丧失合作机遇。

\section{参考文献(References)}

蒋费雯, 罗小龙. 2016. 产业园区合作共建模式分析: 以江苏 省为例 [J]. 城市问题, (7): 38-43. [Jiang F W, Luo X L. 2016. Analysis to the cooperative modes of industrial parks: A case study on Jiangsu Province. Urban Problems, (7): $38-43$. ]

金利霞, 张虹鸥, 殷江滨, 等. 2015. 基于新区域主义的广东 省“核心-外围”区域合作治理: 以广东顺德清远(英德)经 济合作区为例 [J]. 经济地理, 35(4): 19-25. [Jin L X, Zhang H O, Yin J B, et al. 2015. The regional cooperation governance of "core- periphery" in Guangdong Province under the perspective of new regionalism. Economic Geography, 35(4): 19-25. ]

李昕, 文婧, 林坚. 2012. 土地城镇化及相关问题研究综述 [J]. 地理科学进展, 31(8): 1042-1049. [Li X, Wen J, Lin J. 2012. Review of research on land urbanization and related studies. Progress in Geography, 31(8): 1042-1049. ]

李亚娟, 陈田, 王开泳, 等. 2013. 国内外民族社区研究综述 [J]. 地理科学进展, 32(10): 1520-1534. [Li Y J, Chen T, Wang K Y, et al. 2013. Review of ethnic community research. Progress in Geography, 32(10): 1520-1534. ]

连莲, 叶旭廷. 2016. 京津冀协同发展中的“飞地” 经济研究 [J]. 经济问题探索, (5): 146-151. [Lian L, Ye X T. 2016. Research on enclave economy in the coordinated development of Jingjinji region. Inquiry into Economic Issues, (5): 146-151. ]

刘永敬, 罗小龙, 田冬, 等. 2014. 中国跨界新区的形成机制、 空间组织和管治模式初探 [J]. 经济地理, 34(12): 41-47. [Liu Y J, Luo X L, Tian D, et al. 2014. Preliminary study on China's cross-boundary new district in forming mechanisms, spatial organizations and governance models. Economic Geography, 34(12): 41-47. ]

罗小龙, 沈建法. 2006. 中国城市化进程中的增长联盟和反 增长联盟: 以江阴经济开发区靖江园区为例 [J]. 城市规 划, 30(3): 48-52. [Luo X L, Shen J F. 2006. Urban growth coalition and anti-coalition in China's urbanization: A case study of Jiangyin economic development zone in Jingjiang. City Planning Review, 30(3): 48-52. ]

马学广. 2016. 全球城市区域的空间生产与跨界治理研究 
[M]. 北京: 科学出版社. [Ma X G. 2016. Research on spatial production and cross-border governance in global cityregions. Beijing, China: Science Press. ]

苏文松, 方创琳. 2017. 京津冀城市群高科技园区协同发展 动力机制与合作共建模式: 以中关村科技园为例 [J]. 地 理科学进展, 36(6): 657-666. [Su W S, Fang C L. 2017. Dynamic mechanism of coordinated development and collaborative development models of high-tech parks in the Beijing-Tianjin-Hebei: A case study of Zhongguancun Science Park. Progress in Geography, 36(6): 657-666. ]

孙君, 姚建凤. 2011. 产业转移对江苏区域经济发展贡献的 实证分析: 以南北共建产业园为例 [J]. 经济地理, 31(3): 432-436. [Sun J, Yao J F. 2011. Empirical study on contribution of industry transfer to Jiangsu economic development: By the example of southern-northern co-building industrial parks. Economic Geography, 31(3): 432-436. ]

王成龙, 刘慧, 张梦天. 2016. 边界效应研究进展及展望 $[\mathrm{J}]$. 地理科学进展, 35(9): 1109-1118. [Wang C L, Liu H, Zhang M T. 2016. Progress and prospects of border effect research. Progress in Geography, 35(9): 1109-1118. ] 文欣中. 2004. 诸侯经济寻破局: 从开发区到 “飞地经济” [J]. 中国高新区, (4): 20-21. [Wen X Z. 2004. Breaking the duke economy: From development zones to enclave economy. Science and Technology Industry Parks, (4): 2021. ]

杨玲丽. 2015. “嵌人性”约束下的产业转移制度安排: 江苏 省南北挂钩共建产业园区的经验借鉴 [J]. 科技进步与对 策, 32(5): 48-53. [Yang L L. 2015. Industrial transfer system arrangement of embeddedness under the constraint: Experience of establishing industrial park with south and north Jiangsu. Science and Technology Progress and Policy, 32(5): 48-53. ]

张京祥. 2013. 国家-区域治理的尺度重构: 基于“国家战略 区域规划”视角的剖析 [J]. 城市发展研究, 20(5): 45-50. [Zhang J X. 2013. Scale rescaling of regional governance: Based on the analysis of the perspective of "national strategic regional planning". Urban Development Studies, 20(5): 45-50. ]

张京祥, 耿否, 殷洁, 等. 2011. 基于区域空间生产视角的区 域合作治理: 以江阴经济开发区靖江园区为例 $[\mathrm{J}]$. 人文 地理, 26(1): 5-9. [Zhang J X, Geng L, Yin J, et al. 2011. The regional cooperative governance from the perspective of regional spatial production: A case study of Jinjiang Park, Jiangyin Economic Development Zone. Human Geography, 26(1): 5-9. ]

Brenner N. 2004. New state spaces: Urban governance and the rescaling of statehood $[\mathrm{M}]$. Oxford, UK: Oxford Universi- ty Press.

Bustos-Gallardo B. 2017. The post 2008 Chilean Salmon industry: An example of an enclave economy [J]. The Geographical Journal, 183(2): 152-163.

Delaney D. 2005. Territory: A short introduction [M]. Oxford, UK: Blackwell Publishing.

Gallagher K P, Zarsky L. 2007. The enclave economy: Foreign investment and sustainable development in Mexico's silicon valley [M]. Cambridge / London: The MIT Press.

Gualini E. 2004. Regionalization as "experimental regionalism": The rescaling of territorial policy-making in Germany [J]. International Journal of Urban and Regional Research, 28(2): 329-353.

Harvey D. 1982. The limits to capital [M]. Chicago, IL: University of Chicago Press.

Harvey D. 1989. From managerialism to entrepreneurialism: The transformation in urban governance in late capitalism [J]. Geografiska Annaler, 71(1): 3-17.

Jessop B, Sum N. 2016. An entrepreneurial city in action: Hong Kong's emerging strategies in and for (inter)urban competition [J]. Urban Studies, 37(12): 2287-2313.

Johnson C M. 2009. Cross- border regions and territorial restructuring in central Europe $[\mathrm{J}]$. European Urban and Regional Studies, 16(2): 177-191.

Kwon S W, Park S C. 2014. Metropolitan governance: How regional organizations influence interlocal land use cooperation [J]. Journal of Urban Affairs, 36(5): 925-940.

Li Y, Wu F. 2012. The transformation of regional governance in China: The rescaling of statehood [J]. Progress in Planning, 78(2): 55-99.

Light I, Sabagh G, Bozorgmehr M, et al. 1994. Beyond the ethnic enclave economy [J]. Social Problems, 41(1): 65-80.

Perkmann M. 2007. Construction of new territorial scales: A framework and case study of the EUREGIO cross-border region [J]. Regional Studies, 41(2): 253-266.

Pikner T. 2008. Reorganizing cross-border governance capacity: The case of the Helsinki-Tallinn Euregio [J]. European Urban and Regional Studies, 15(3): 211-227.

Smith N. 1990. Uneven development: Nature, capital, and the production of space [M]. Oxford, UK: Basil Blackwell.

Wingfield A H. 2009. Doing business with beauty: Black women, hair salons, and the racial enclave economy [M]. Lanham, MD: Rowman and Littlefield Publishers.

Wu F. 2016. China's emergent city-region governance: A new form of state spatial selectivity through state-orchestrated rescaling $[\mathrm{J}]$. International Journal of Urban and Regional Research, 40(6): 1134-1151. 


\title{
The production and governance structure of enclave economy: From the perspective of state spatial restructuring
}

\author{
LI Luqi ${ }^{1}$, MA Xueguang ${ }^{2 *}$, LU Yu ${ }^{2}$ \\ (1. School of Urban and Regional Science, East China Normal University, Shanghai 200241, China; \\ 2. School of International Affairs and Public Administration, Ocean University of China, Qingdao 266100, Shandong, China)
}

\begin{abstract}
The state space has undergone significant transformations in China since 2000, changing from urban entrepreneurialism to regionalization. In this context, enclave economy is emerging and developing in various regions, and has been studied by researchers in a range of fields. However, most of the existing studies focus on the microscopic mechanisms and modes, without more detailed analyses of the macroscopic and structural factors behind this phenomenon. Apparently, this approach is problematic because enclave economy is not only a grassroots strategy, but also an integral part of the spatial strategies at the national scale in recent years. Therefore, based on the theories of state spatial restructuring, this article analyzes how enclave economy is produced and what governance structures are formed in this process. It suggests that enclave economy is driven by the crisis of capital accumulation and the tendency of reterritorialization. In this context, it originates from bottom- up institutional experiments, and then becomes a flexible yet inadequate strategy of regionalization. Following this, due to the consistency between enclave economy and the evolution of state spatial selectivity, it is then integrated into China's state spatial strategies that focus on the competitiveness of city-regions. Moreover, the governance structure of enclave economy includes inter-scalar, inter- territorial, and government-market relations, which are contingent, complex, and relatively fragile. In sum, this practice should be viewed as an emerging experiment in the state spatial restructuring, whose effects and consequences remain to be seen.
\end{abstract}

Keywords: enclave economy; co-development industrial parks; new state space; rescaling; regionalization; China 